\title{
A case of radiation-induced osteosarcoma treated effectively by boron neutron capture therapy
}

\author{
Gen Futamura', Shinji Kawabata', Hiroyuki Siba', Toshihiko Kuroiwa' ${ }^{1}$, Minoru Suzuki², Natsuko Kondo², Koji Ono², \\ Yoshinori Sakurai ${ }^{3}$, Minoru Tanaka ${ }^{4}$, Tomoki Todo ${ }^{4}$ and Shin-lchi Miyatake ${ }^{5^{*}}$
}

\begin{abstract}
We treated a 54-year-old Japanese female with a recurrent radiation-induced osteosarcoma arising from left occipital skull, by reactor-based boron neutron capture therapy (BNCT). Her tumor grew rapidly with subcutaneous and epidural extension. She eventually could not walk because of cerebellar ataxia. The tumor was inoperable and radioresistant. BNCT showed a marked initial therapeutic effect: the subcutaneous/epidural tumor reduced without radiation damage of the scalp except hair loss and the patient could walk again only 3 weeks after BNCT. BNCT seems to be a safe and very effective modality in the management of radiation-induced osteosarcomas that are not eligible for operation and other treatment modalities.
\end{abstract}

\section{Introduction}

The incidence of radiation-induced sarcoma has been estimated to be between $0.03 \%$ and $0.3 \%$ of all patients who have received radiation therapy [1,2]. Radiationinduced osteosarcomas are being encountered more frequently as the use of radiation therapy becomes more common, and the number of long-term cancer survivors has increased. The original diagnostic criteria for radiation-induced osteosarcomas were proposed in 1948 by Cahan et al. [3], and a short latency period was recently accepted for these tumors $[1,4,5]$. The diagnosis of radiation-induced osteosarcoma must fulfill the following four criteria: (1) the sarcoma must arise in a previously irradiated field, (2) the sarcoma must be histologically distinct from the original neoplasm, (3) there was no evidence of tumor in the involved bone at the time of initial irradiation, and (4) there must be a latency period between the irradiation and the development of the sarcoma at least 3 years.

Radiation-induced osteosarcoma of the head is a devastating complication of radiation therapy. It is very rare but aggressive, with high recurrence and a poor prognosis [6]. The median overall survival time was reported to be 29 months [1]. Osteosarcoma is thought to be radioresistant $[7,8]$. Therefore, complete surgical resection

\footnotetext{
* Correspondence: neu070@poh.osaka-med.ac.jp

${ }^{5}$ Cancer Center, Osaka Medical College, Takatsuki, Japan

Full list of author information is available at the end of the article
}

has been described as the most important prognostic factor [9] and the first choice of treatment for radiationinduced osteosarcoma. However, if complete surgical resection is difficult (as it was in the present case), adjuvant chemotherapy and radiotherapy should be considered. These therapeutic effects have thus far been found to be insufficient, however. We report here the case of a patient with recurrent radiation-induced osteosarcoma who was treated effectively by boron neutron capture therapy (BNCT).

BNCT is based on the nuclear capture reactions that occur when non-radioactive boron-10 is irradiated with neutrons of the appropriate energy to yield high linear energy transfer (LET) alpha particles $(4 \mathrm{He})$ and recoiling lithium-7 (7Li) nuclei. Since these particles have short pathlengths of approximately one cell diameter, their lethality is primarily limited to boron-containing cells. Theoretically, high LET particles have the advantage to overcome radioresistance to photon radiotherapies (such as X-rays). BNCT can thus be regarded as tumor cell-selective and an intensive particle radiation modality with minimal damage to normal tissue, $[10,11]$ even for X-ray-resistant tumors. Here we report a successfully treated a case of radiationinduced osteosarcoma by reactor-based BNCT.

\section{Case report}

A 54-year-old Japanese female was referred to our institute for treatment by BNCT of a recurrent radiation-induced 
osteosarcoma involving the left occipital bone. Ten years earlier, she was diagnosed with cancer of the uterine body and underwent resection surgery. Two years after that surgery, she underwent chemotherapy and whole-brain radiation therapy (WBRT, total 30 Gy with 10 fractions) including the cerebellum for brain metastasis. Six years after the WBRT, she was diagnosed with a radiationinduced osteosarcoma involving the left occipital bone, and she underwent resection surgery and successive chemotherapy using methotrexate. One year after that surgery and chemotherapy, the subcutaneous tumor appeared again in the left occipital region and rapidly enlarged over a period of only 3 months (Figure 1A). Magnetic resonance images (MRI) showed the epidural tumor invasion (Figure 2A and A'). Eventually, the patient could not walk because of acutely developing cerebellar ataxia. This tumor was diagnosed as a recurrence of the radiation-induced osteosarcoma in accord with the above Cahan's criteria [3].

We performed BNCT for the radiation-induced osteosarcoma because the lesion/normal brain $(\mathrm{L} / \mathrm{N})$ ratio of fluoride-labeled boronophenylalanine positron emission tomography (FBPA-PET) was enough high, as shown in Figure $3 \mathrm{~A}$ and $\mathrm{B}$ (L/N ratio: 3.8) [12]. For the BNCT, neutron irradiation was applied at Kyoto University Reactor.

The patient was administered $500 \mathrm{mg} / \mathrm{kg}$ of BPA intravenously for 3.2 hours $(200 \mathrm{mg} / \mathrm{kg}$ for initial 2 hours, prior to neutron irradiation, $100 \mathrm{mg} / \mathrm{kg}$ for 1.2 hours during neutron irradiation). The boron concentration in the blood was monitored by sampling every 1 hour after boron compound administration until neutron irradiation was completed. The boron concentrations from BPA in the tumor and normal brain were estimated from the $\mathrm{L} / \mathrm{N}$ ratio of $18 \mathrm{~F}$-BPA on PET. The neutron fluence rate was simulated by the dose-planning system, SERA (Idaho
National Engineering and Environmental Laboratory, Idaho Falls, ID) and the total doses to the tumor and normal brain were simulated. The neutron irradiation time was determined not to exceed $13 \mathrm{~Gy}$-Eq to the normal brain in accordance with our recent protocol of BNCT for high-grade meningiomas [10]. For this case, irradiation time was 70 minutes and B10 concentration of the venous blood was judged as $37.2 \mathrm{ppm}$ during the neutron irradiation. Here, Gy-Eq (Gy: Gray) means an X-ray dose that can give biologically equivalent effects to total BNCT radiation. The scalp just above the tumor was covered with the bolus composed of sodium polyacrylate with $1 \mathrm{~cm}$-thickness to gain the superficial neutron flux. After the treatment, the doses given were re-estimated precisely and are shown in Table 1. We hypothesized the boron concentrations of the blood, brain, and skin were equal, as we did in the previous BNCT. RBE and CBE values employed here were listed in Table 2.

Absorbed physical dose and X-ray-equivalent dose (Gy-Eq) are calculated with the following formula;

$$
\begin{aligned}
& \mathrm{E}_{\text {Total }}= \mathrm{E}_{\mathrm{B} 10}+\mathrm{E}_{\text {Thermal }}+\mathrm{E}_{\text {Fast }}+\mathrm{E}_{\gamma} \\
& \mathrm{E}_{\mathrm{B} 10}=\left(\mathrm{C}_{\mathrm{BSH}} \times \mathrm{CBE}_{\mathrm{BSH}}+\mathrm{C}_{\mathrm{BPA}} \times \mathrm{CBE}_{\mathrm{BPA}}\right) \times 7.43 \\
& \times 10^{-14} \times \Phi_{\text {Thermal }} \\
& \mathrm{E}_{\text {Thermal }}=\mathrm{N} \times \mathrm{RBE}_{\text {Thermal }} \times 6.78 \times 10^{-14} \times \Phi_{\text {Thermal }} \\
& \mathrm{E}_{\text {Fast }}= \mathrm{RBE}_{\text {Fast }} \times \mathrm{D}_{\text {Fast }} \\
& \mathrm{E}_{\gamma}= \mathrm{RBE}_{\gamma} \times \mathrm{D}_{\gamma}
\end{aligned}
$$

D: physical absorbed dose (Gy),

ФThermal: fluence of theraml neutron (cm-2),

$\mathrm{N}$ : nitrogen concentration $(2 \%$, here)

$\mathrm{C}: \mathrm{B} 10$ concentration (ppm).

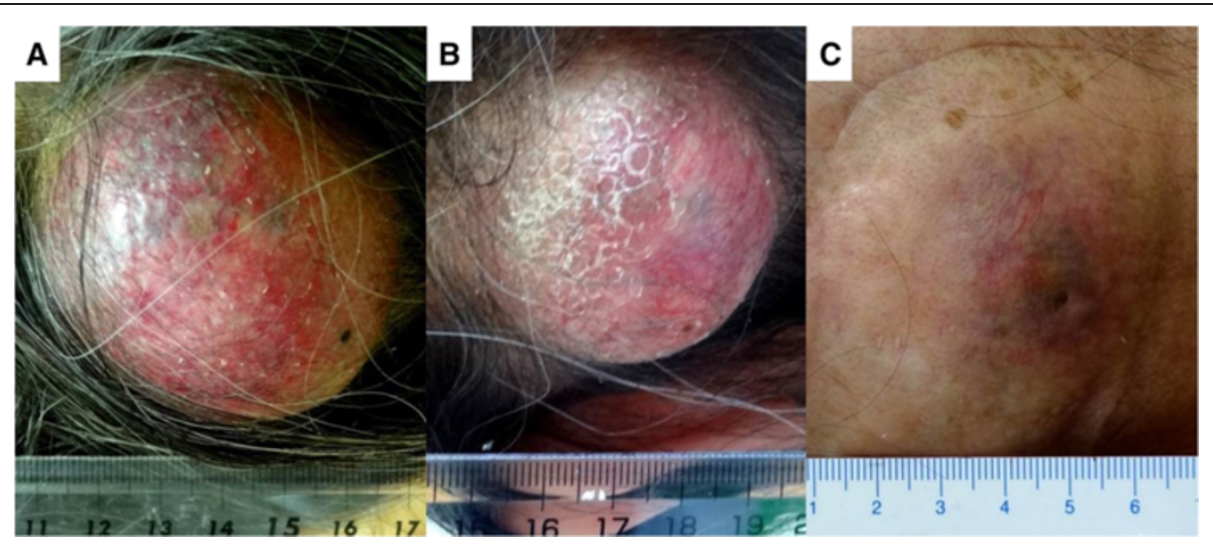

Figure 1 Marked improvement of the subcutaneous tumor at 3 weeks after the application of BNCT. A: Just prior to the BNCT; the tumor is elastic hard, and painful. B: Seven days after the BNCT; the tumor is soft and no longer painful. C: At 2 months after the BNCT, the tumor had shrunk drastically without radiation damage to the skin. 


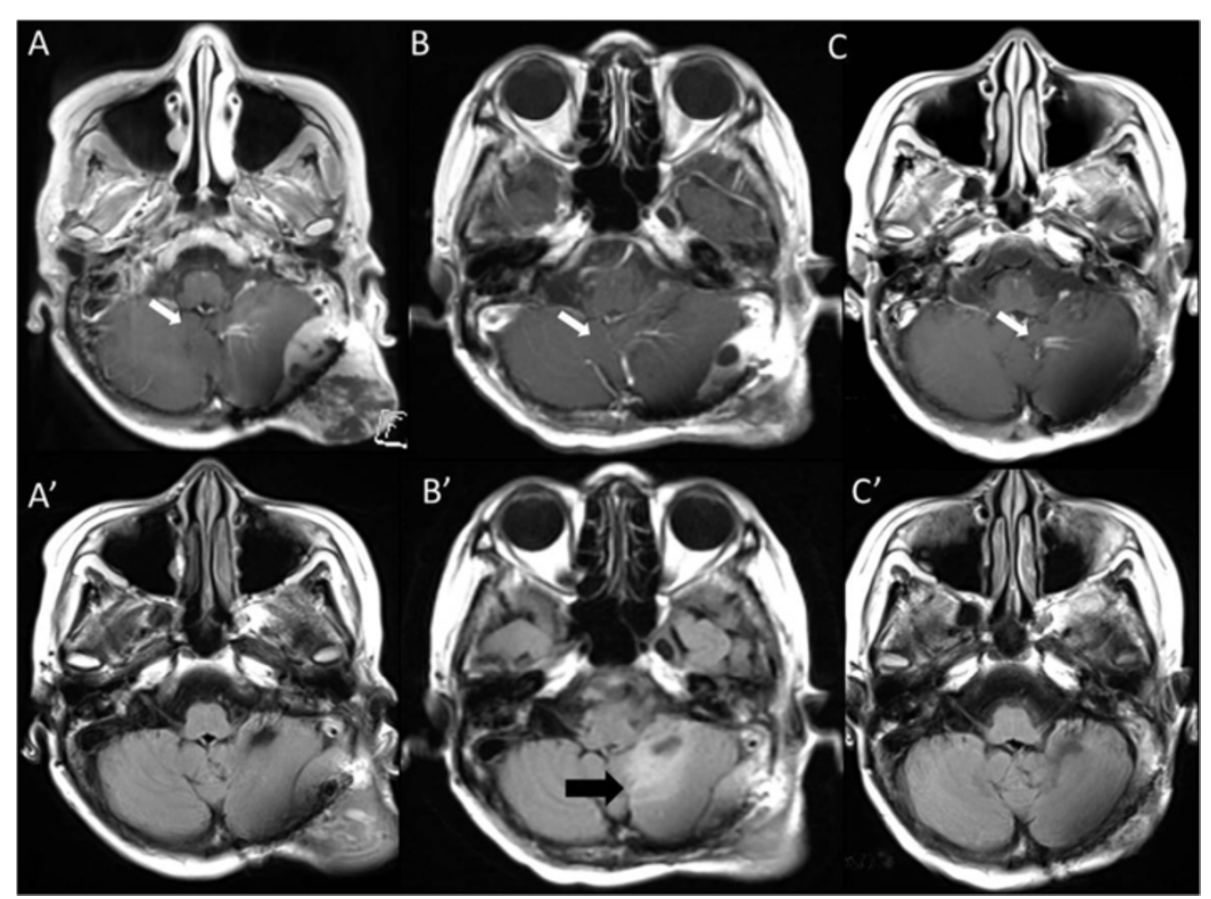

Figure 2 MRI of the patient's brain before and after the BNCT. White arrows indicate a venous angioma, which was recognized incidentally and judged as a sectional standard of MRI. A: Gd-enhanced T1-weighted MRI of the brain 1 month before the BNCT. There was a subcutaneous and epidural tumor mass. B: Gd-enhanced T1-weighted MRI at 4 days after BNCT. The tumor mass was reduced. C: Gd-enhanced T1-weighted MRI of the brain 3 months after BNCT. The tumor mass was further reduced. A': Fluid-attenuated inversion recovery (FLAIR) MRI of the brain 1 month before BNCT. B': FLAIR MRI of the brain 4 days after BNCT. The tumor mass was reduced, but the edema had worsened. A black arrow indicates the cerebellar edema. $\mathbf{C}^{\prime}$ : FLAIR MRI of the brain 3 months after BNCT. The tumor mass was further reduced, and the edema had disappeared.

For this patient, we estimated that the minimum tumor and maximum normal brain and skin doses were 67.7, 12.7 and 12.4 Gy-Eq, respectively in the BNCT, simulated from F-BPA-PET imaging and the blood BPA concentration (Table 1).

At one day after the BNCT, the patient's gait disturbance was aggravated. Computed tomography at that time showed aggravation of peri-lesional edema (data not shown). Remarkably, the MRI taken 4 days after the BNCT demonstrated the definitive shrinkage of the mass, but the left cerebellar edema was still there (Figure 2B and B'). We then treated the edema with dehydrators and steroids. The symptoms gradually improved.

At only 3 weeks after the BNCT, the patient was able to walk again stably without aid. The subcutaneous tumor was reduced dramatically without radiation injury of the scalp, with time after BNCT, as shown in Figure 1B and C. The only adverse effect was hair loss in neutron-irradiation field, as shown in Figure 1C. MRI showed the further reduction of tumor and the disappearance of the cerebellar edema (Figure $2 \mathrm{C}$ and $\mathrm{C}^{\prime}$ ), 3 months after BNCT. Also F-BPA-PET taken 2 months after BNCT showed faint tracer uptake, indicating some metabolic change at least by this treatment (Figure 3A' and B', L/N ratio as 1.2).

\section{Discussion}

Radiation-induced osteosarcoma is not common. It has an aggressive nature, high recurrence rate, and poor prognosis. A standard therapy protocol has not yet been established for non-resectable tumors, but it was reported that particle radiotherapy (treatment with proton and carbon beams) had a therapeutic effect on these tumors [7,13].

In the present case, the tumor was chemo-resistant and difficult to totally resect because it invaded the left transverse and sigmoid venous sinuses. In addition, the subcutaneously extended tumor invaded the surface of the skin, and we thus suspected that a skin deficit due to surgery was inevitable and that particle radiotherapy for this tumor was likely to cause severe radiation-induced adverse effects on the scalp. The tumor was radiationinduced, and the cerebellum and overlying scalp had a history of X-ray treatment. Moreover, osteosarcomas have the characteristic of being radioresistant, i.e., Xray-resistant. In light of these medical circumstances, we chose BNCT as the treatment modality for this patient. In the present case, the patient was successfully treated by BNCT without skin damage even though her tumor invaded the superficial scalp. 


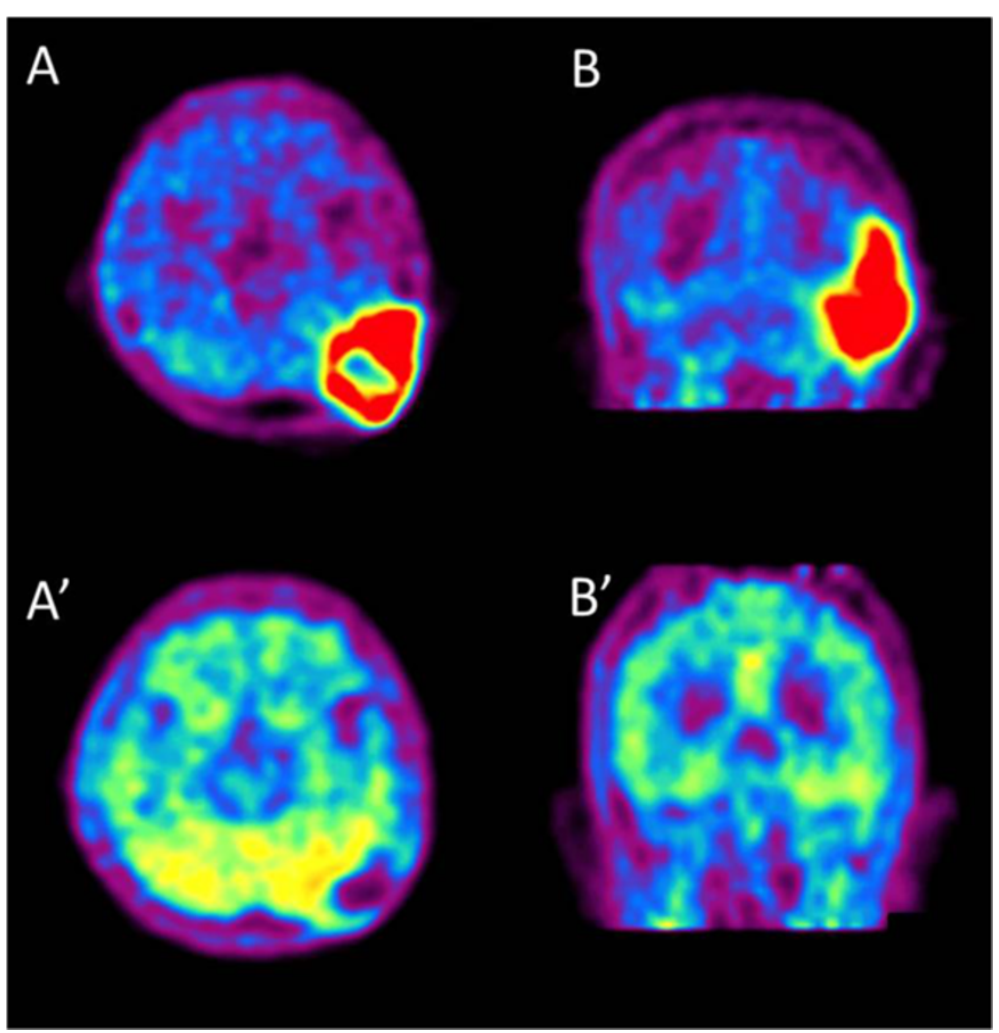

Figure 3 Fluoride-labeled boronophenylalanine-PET imaging of the brain before and after BNCT. Fluoride-labeled boronophenylalanine-PET imaging taken 1 month prior to BNCT (A and $\mathbf{B}$ ) and 2 months after BNCT ( $\mathbf{A}^{\prime}$ and $\mathbf{B}^{\prime}$ ). $\mathbf{A}$ and $\mathbf{A}^{\prime}$ : axial imaging, $\mathbf{B}$ and $\mathbf{B}^{\prime}$ : coronal imaging. In $\mathbf{A}$ and $\mathbf{B}$, $\mathrm{L} / \mathrm{N}$ ratio was calculated as 5.0. This is theoretical proof of tumor selective destruction using BPA in BNCT. Also absorbed doses were simulated with this $\mathrm{L} / \mathrm{N}$ ratio. 2 months after $B N C T, \mathbf{A}^{\prime}$ and $\mathbf{B}^{\prime}$ show the decreased $L / N$ ratio as 1.2, indicating the marked effectiveness.

We recently reported the effectiveness of BNCT for radiation-refractory high-grade meningiomas [10]. In that report, we speculated that the difference in tumor shrinkage between the alpha and lithium particles provided by BNCT and other particles such as carbon and protons may be ascribed to the difference in LET noted above and their fraction size [10].

Other types of particle radiotherapy and some stereotactic radiotherapies which have been tried recently for tumors were applied as multi-fraction. The reduction of

Table 1 Estimated dose distribution at the central axis of neutron-irradiation field

\begin{tabular}{|c|c|c|c|c|c|c|c|c|}
\hline $\begin{array}{l}\text { Depth } \\
\text { (cm) }\end{array}$ & $\begin{array}{l}\text { Total dose } \\
\text { (tumor) (Gy-eq) }\end{array}$ & $\begin{array}{l}\text { Total dose } \\
\text { (skin) (Gy-eq) }\end{array}$ & $\begin{array}{l}\text { Total dose } \\
\text { (mucosa) (Gy-eq) }\end{array}$ & $\begin{array}{l}\text { Total dose } \\
\text { (brain) (Gy-eq) }\end{array}$ & $\begin{array}{l}\text { Thermal } \\
\text { neutron (Gy-eq) }\end{array}$ & $\begin{array}{l}\text { Fast } \\
\text { neutron (Gy-eq) }\end{array}$ & $\begin{array}{l}\text { Y-ray } \\
\text { (Gy-eq) }\end{array}$ & $\begin{array}{l}\text { Boron dose } \\
\text { (tumor) (Gy-eq) }\end{array}$ \\
\hline 0.00 & $5.28 \mathrm{E}+01$ & $1.24 \mathrm{E}+01$ & $2.08 \mathrm{E}+01$ & $8.37 E+00$ & 5.05E-01 & $2.13 E+00$ & $1.00 \mathrm{E}+00$ & $4.92 \mathrm{E}+01$ \\
\hline 0.50 & $6.79 E+01$ & 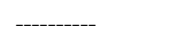 & $2.61 E+01$ & $9.90 E+00$ & $6.56 \mathrm{E}-01$ & $1.87 \mathrm{E}+00$ & $1.22 \mathrm{E}+00$ & $6.41 E+01$ \\
\hline 1.00 & $8.06 \mathrm{E}+01$ & --- & $3.06 \mathrm{E}+01$ & $1.12 \mathrm{E}+01$ & 7.83E-01 & $1.64 \mathrm{E}+00$ & $1.43 \mathrm{E}+00$ & $7.67 \mathrm{E}+01$ \\
\hline 1.50 & $8.47 \mathrm{E}+01$ & . & $3.20 E+01$ & $1.16 \mathrm{E}+01$ & $8.24 \mathrm{E}-01$ & $1.35 E+00$ & $1.63 E+00$ & $8.09 \mathrm{E}+01$ \\
\hline 2.00 & $9.00 \mathrm{E}+01$ & & $3.39 E+01$ & $1.21 E+01$ & 8.77E-01 & $1.17 \mathrm{E}+00$ & $1.80 \mathrm{E}+00$ & $8.62 \mathrm{E}+01$ \\
\hline 2.50 & $9.38 \mathrm{E}+01$ & & $3.53 E+01$ & $1.26 \mathrm{E}+01$ & $9.13 \mathrm{E}-01$ & $1.11 E+00$ & $1.92 E+00$ & $8.98 \mathrm{E}+01$ \\
\hline 3.00 & $9.55 \mathrm{E}+01$ & & $3.58 \mathrm{E}+01$ & $1.27 \mathrm{E}+01$ & $9.31 \mathrm{E}-01$ & $9.77 \mathrm{E}-01$ & $2.02 \mathrm{E}+00$ & $9.16 \mathrm{E}+01$ \\
\hline 3.50 & $9.53 \mathrm{E}+01$ & & $3.57 E+01$ & $1.27 \mathrm{E}+01$ & $9.30 \mathrm{E}-01$ & 8.63E-01 & $2.09 E+00$ & $9.14 \mathrm{E}+01$ \\
\hline 4.00 & $9.18 \mathrm{E}+01$ & & $3.44 \mathrm{E}+01$ & $1.22 \mathrm{E}+01$ & 8.94E-01 & 7.72E-01 & $2.11 \mathrm{E}+00$ & $8.80 E+01$ \\
\hline 4.50 & $8.62 \mathrm{E}+01$ & & $3.24 \mathrm{E}+01$ & $1.16 \mathrm{E}+01$ & 8.38E-01 & $6.91 \mathrm{E}-01$ & $2.10 \mathrm{E}+00$ & $8.26 \mathrm{E}+01$ \\
\hline 5.00 & $7.97 \mathrm{E}+01$ & --- & $3.00 E+01$ & $1.08 \mathrm{E}+01$ & 7.74E-01 & $6.18 \mathrm{E}-01$ & $2.08 \mathrm{E}+00$ & $7.62 \mathrm{E}+01$ \\
\hline 5.50 & $7.15 E+01$ & ------- & $2.70 E+01$ & $9.79 E+00$ & $6.93 \mathrm{E}-01$ & 5.54E-01 & $1.99 \mathrm{E}+00$ & $6.82 \mathrm{E}+01$ \\
\hline 5.80 & $6.77 E+01$ & - & $2.56 \mathrm{E}+01$ & $9.31 E+00$ & $6.55 E-01$ & $5.12 \mathrm{E}-01$ & $1.95 E+00$ & $6.45 E+01$ \\
\hline
\end{tabular}


Table 2 RBE (relative biological effectiveness) factor

\begin{tabular}{llll}
\hline Radiation & Tumor & Brain & Skin \\
\hline Thermal neuton & 3.0 & 3.0 & 3.0 \\
Epithermal neutron & 3.0 & 3.0 & 3.0 \\
${ }^{10} \mathrm{~B}(\mathrm{n}, \mathrm{a})^{7} \mathrm{Li}: \mathrm{BPA}$ & 3.8 & 1.35 & 2.5 \\
$\mathrm{Y}$-ray dose & 1.0 & 1.0 & 1.0 \\
\hline
\end{tabular}

the tumor mass was thus not very prominent, and it was difficult to improve the patients' symptoms by means other than BNCT. BNCT can deliver high dose particles in a tumor-selective fashion in a single session, and in some cases the resulting reduction of the tumor was fast; this rapid shrinkage might contribute to the prompt elimination of symptoms [10]. Indeed, the present patient, within a very short time, exhibited improvement of her gait disturbance due to cerebellar ataxia.

Only a couple of articles were published with regard to pre-clinical study of BNCT for osteosarcoma in in vitro cell culture and animal experiments [14-17]. Among them, Russian research group reported successful treatment of dog osteosarcoma case by BNCT. Also only one preliminary report was published with regard to a BNCTtreated osteosarcoma case in head and neck region with limited description, so far [18]. We are not sure of the compound biological effectiveness (CBE) of BPA for osteosarcomas, and we were only able to estimate CBE as being the same for glioblastoma (i.e., 3.8) [19] as we did for high-grade meningioma [10]. For the estimation of the prescribed dose for this case, we adopted the reported value of CBE and relative biological effectiveness of neutron itself for tumors and normal tissues [20]. Thereafter the estimated tumor dose was uncertain in this case. However, as a result of the BNCT, the tumor shrank rapidly, the patient's clinical symptoms improved, metabolically scarce uptake of the amino-acid tracer was observed in the follow-up PET imaging and no serious damage was observed in the scalp and brain, so far at 6 months after BNCT, although the observation period was short.

Based on this outcome, we found that BNCT was an effective treatment for our patient. However, careful follow-up or the use of bevacizumab may be necessary in some cases [21], because WBRT that has been already performed may cause brain radiation necrosis.

We experienced only a case of successful treatment of BNCT for radiation-induced osteosacoma. Hopefully these potential therapeutic effects will be applicable for non-radiation-induced osteosarcomas which are generally refractory for other treatment modalities.

\section{Conclusions}

BNCT is an effective treatment for non-resectable radiationinduced skull osteosarcoma. We suggest that BNCT is the only effective therapy for tumors that have invaded the skin. Further applications of BNCT for similar cases are expected.

\section{Competing interests}

The authors declare that they have no competing interests.

\section{Authors' contributions}

S-IM conceived of the study and participated in the follow-up of the patient. GF, SK, NK, MS and KO applied BNCT in the atomic reactor. YS simulated BNCT dose. HS and TK participated in patient care in the hospital. MT and TT referred the patient for S-IM and also participated in the patient care and follow-up at the out-patient clinic. All authors read and approved the final manuscript.

\section{Acknowledgement}

We appreciate Dr. Silva Bortolussi, National Institute for Nuclear Physics (INFN) Section of Pavia, Italy for the critical reading of the manuscript and fruitful discussion.

\section{Author details}

${ }^{1}$ Department of Neurosurgery, Osaka Medical College, Takatsuki, Japan. ${ }^{2}$ Particle Radiation Oncology Research Center, Kyoto University Research Reactor Institute, Kumatori, Japan. ${ }^{3}$ Division of Radiation Life Science, Kyoto University Research Reactor Institute, Kumatori, Japan. ${ }^{4}$ Division of Innovative Cancer Therapy, and Department of Surgical Neuro-Oncology The Institute of Medical Science, The University of Tokyo, Tokyo, Japan. ${ }^{5}$ Cancer Center, Osaka Medical College, Takatsuki, Japan.

Received: 8 September 2014 Accepted: 14 October 2014 Published online: 04 November 2014

\section{References}

1. Patel AJ, Rao VY, Fox BD, Suki D, Wildrick DM, Sawaya R, DeMonte F: Radiation-induced osteosarcomas of the calvarium and skull base. Cancer 2011, 117:2120-2126.

2. Amendola BE, Amendola MA, McClatchey KD, Miller CH Jr: Radiation-associated sarcoma: a review of 23 patients with postradiation sarcoma over a 50-year period. Am J Clin Oncol 1989, 12:411-415.

3. Cahan WG, Woodard HQ, Higinbotham N, Stewart F, Coley B: Sarcoma arising in irradiated bone; report of 11 cases. Cancer 1948, 1:3-29.

4. Arlen M, Higinbotham NL, Huvos AG, Marcove RC, Miller T, Shah IC: Radiation-induced sarcoma of bone. Cancer 1971, 28:1087-1099.

5. Murray EM, Werner D, Greeff EA, Taylor DA: Postradiation sarcomas: 20 cases and a literature review. Int J Radiat Oncol Biol Phys 1999, 45:951-961.

6. Patel RD, Gadgil NM, Khare M, Majethia N: Radiation-induced intracranial osteosarcoma: a case report. J Postgrad Med 2014, 60:218-219.

7. Imai R, Kamada T, Tsuji H, Tsujii H, Tsuburai Y, Tatezaki S: Cervical spine osteosarcoma treated with carbon-ion radiotherapy. Lancet Oncol 2006, 7:1034-1035.

8. Mankin HJ, Hornicek FJ, Rosenberg AE, Harmon DC, Gebhardt MC: Survival data for 648 patients with osteosarcoma treated at one institution. Clin Orthop Relat Res 2004, 429:286-291.

9. Granados-Garcia M, Luna-Ortiz K, Castillo-Oliva HA, Villavicencio-Valencia V, Herrera-Gomez A, Mosqueda-Taylor A, Aguilar-Ponce JL, Poitevin-Chacon A: Free osseous and soft tissue surgical margins as prognostic factors in mandibular osteosarcoma. Oral Oncol 2006, 42:172-176.

10. Kawabata S, Hiramatsu R, Kuroiwa T, Ono K, Miyatake S: Boron neutron capture therapy for recurrent high-grade meningiomas. J Neurosurg 2013, 119:837-844.

11. Kawabata S, Yang W, Barth RF, Wu G, Huo T, Binns PJ, Riley KJ, Ongayi O, Gottumukkala V, Vicente MG: Convection enhanced delivery of carboranylporphyrins for neutron capture therapy of brain tumors. J Neuro-Oncol 2011, 103:175-185.

12. Miyashita M, Miyatake S, Imahori Y, Yokoyama K, Kawabata S, Kajimoto $Y$, Shibata MA, Otsuki Y, Kirihata M, Ono K, Kuroiwa T: Evaluation of fluoride-labeled boronophenylalanine-PET imaging for the study of radiation effects in patients with glioblastomas. J Neuro-Oncol 2008, 89:239-246

13. Blattmann C, Oertel S, Schulz-Ertner D, Rieken S, Haufe S, Ewerbeck V, Unterberg A, Karapanagiotou-Schenkel I, Combs SE, Nikoghosyan A, Bischof $M$, Jakel O: Non-randomized therapy trial to determine the safety and 
efficacy of heavy ion radiotherapy in patients with non-resectable osteosarcoma. BMC Cancer 2010, 10:96.

14. Bortolussi S, Ciani L, Postuma I, Protti N, Luca R, Bruschi P, Ferrari C, Cansolino L, Panza L, Ristori S, Altieri S: Boron concentration measurements by alpha spectrometry and quantitative neutron autoradiography in cells and tissues treated with different boronated formulations and administration protocols. Appl Radiat Isot 2014, 88:78-80.

15. Ferrari C, Zonta C, Cansolino L, Clerici AM, Gaspari A, Altieri S, Bortolussi S, Stella S, Bruschi P, Dionigi P, Zonta A: Selective uptake of p-boronophenylalanine by osteosarcoma cells for boron neutron capture therapy. Appl Radiat Isot 2009, 67:S341-S344.

16. Mitin VN, Kulakov VN, Khokhlov VF, Sheino LN, Bass LP, Kozolofskaya NG, Zaitsev KN, Potnov AA, Yagnikov SA, Shiraev SV: BNCT for Canine Osteosarcoma from Advances in Neutron Capture Therapy 2006. In Proceedings of $12^{\text {th }}$ International Congress on Neutron Capture Therapy. 9-13 October 2006. Edited by Nakagawa Y. 2006:135-138.

17. Hsu CF, Lin SY, Peir JJ, Liao JW, Lin YC, Chou FI: Potential of usingboric acid as a boron drug for boron neutron capture therapy for osteosarcoma. Appl Radiat Isot 2011, 69:1782-1785.

18. Kato I, Ono K, Sakurai Y, Ohmae M, Maruhashi A, Imahori Y, Kirihata M, Nakazawa M, Yura Y: Effectiveness of BNCT for recurrent head and neck malignancies. Appl Radiat Isot 2004, 61:1069-1073.

19. Miyatake S, Kawabata S, Kajimoto Y, Aoki A, Yokoyama K, Yamada M, Kuroiwa T, Tsuji M, Imahori Y, Kirihata M, Sakurai Y, Masunaga S, Nagata K, Maruhashi A, Ono K: Modified boron neutron capture therapy for malignant gliomas performed using epithermal neutron and two boron compounds with different accumulation mechanisms: an efficacy study based on findings on neuroimages. J Neurosurg 2005, 103:1000-1009.

20. Coderre JA, Morris GM: The radiation biology of boron neutron capture therapy. Radiat Res 1999, 151:1-18.

21. Miyatake S, Kawabata S, Hiramatsu R, Furuse M, Kuroiwa T, Suzuki M: Boron neutron capture therapy with bevacizumab may prolong the survival of recurrent malignant glioma patients: four cases. Radiat Oncol 2014, 9:6.

doi:10.1186/s13014-014-0237-z

Cite this article as: Futamura et al:: A case of radiation-induced osteosarcoma treated effectively by boron neutron capture therapy. Radiation Oncology 2014 9:237.

\section{Submit your next manuscript to BioMed Central and take full advantage of:}

- Convenient online submission

- Thorough peer review

- No space constraints or color figure charges

- Immediate publication on acceptance

- Inclusion in PubMed, CAS, Scopus and Google Scholar

- Research which is freely available for redistribution 